\title{
Case closed: another prophylactic cranial irradiation trial for stage 3 non-small cell lung cancer fails to improve overall survival
}

\author{
Nuriel Moghavem ${ }^{1}$, Heather A. Wakelee ${ }^{2}$, Seema Nagpal ${ }^{1}$ \\ ${ }^{1}$ Department of Neurology, ${ }^{2}$ Department of Medicine, Stanford University School of Medicine, Palo Alto, CA, USA \\ Correspondence to: Dr. Seema Nagpal. 875 Blake Wilbur Drive CC2221, Stanford, CA 94305, USA. Email: snagpal@stanford.edu. \\ Provenance: This is an invited Editorial commissioned by Section Editor Song $\mathrm{Xu}, \mathrm{MD}, \mathrm{PhD}$ (Department of lung cancer surgery, Tianjin Medical \\ University General Hospital, Tianjin, China; Tianjin Key Laboratory of Lung Cancer Metastasis and Tumor Microenvironment, Lung Cancer \\ Institute, Tianjin, China). \\ Comment on: De Ruysscher D, Dingemans AC, Praag J, et al. Prophylactic Cranial Irradiation Versus Observation in Radically Treated Stage III Non- \\ Small-Cell Lung Cancer: A Randomized Phase III NVALT-11/DLCRG-02 Study. J Clin Oncol 2018;36:2366-77.
}

Submitted Nov 27, 2018. Accepted for publication Dec 10, 2018.

doi: $10.21037 /$ atm.2018.12.24

View this article at: http://dx.doi.org/10.21037/atm.2018.12.24

In a recent study published by De Ruysscher et al. (1), the use of prophylactic cranial irradiation (PCI) significantly reduced the rate of symptomatic brain metastasis development in patients with stage 3 non-small-cell lung cancer (NSCLC) at 2 years. Patients with WHO performance status $0-2$ undergoing chemoradiotherapy with or without surgery for their stage 3 disease were randomized to an observation arm or a treatment arm that underwent PCI (36 Gy in 18 fractions, 30 Gy in 12 fractions, or $30 \mathrm{~Gy}$ in 10 fractions). Symptomatic brain metastases occurred at 2 years in $27.2 \%$ in the observed patients and $7.0 \%$ in the treated patients for a number needed to treat of 4.95 to prevent a case of symptomatic brain metastasis. The intervention improved time to develop symptomatic brain metastases, but not brain metastasis-free survival or, importantly, overall survival (OS). More patients in the intervention arm developed neurologic toxicity, most significantly complaining of grade 1 and 2 headaches, cognitive changes (19\% with PCI, 3\% without) and memory difficulties (30\% with PCI, $8 \%$ without); the latter two changes persisted well beyond the 2-year primary endpoint.

These results lead us to ask: after multiple studies, why hasn't PCI led to meaningful changes in OS, and how should we weigh the demonstrated neurocognitive effects if recommending this palliative treatment to patients?

Brain metastases are an unfortunately common complication of Stage 3 NSCLC, occurring in about $30 \%$ of patients at 2 years (2). Because CNS progression portends high mortality (3) and reductions in quality of life (4), there remains strong interest in preventing brain metastases. In small-cell lung cancer (SCLC), low dose PCI has been found to improve OS and is considered standard of care (5). But as De Ruysscher et al. point out, study of PCI for NSCLC has consistently shown a lack of impact on OS (Table 1), including in systematic review (13) and at 10-year follow-up (14). Moreover, all of the studies investigating this question closed early due to poor accrual; difficulty recruiting patients in trials studying whole brain radiation therapy (WBRT) has been previously observed, thought to be due to existing clinician and patient preference against the treatment (15).

There may be several reasons for the continued lack of an identifiable effect on OS for patients with stage 3 NSCLC treated with PCI.

The first may be due to changing rates of brain metastasis in stage 3 NSCLC. While prior studies have reported rates of intracranial metastasis at $30 \%$ for stage 3 NSCLC at 2 years, it appears that baseline may be lower today. In the PACIFIC trial (PD-L1 inhibitor vs. placebo for stage 3 NSCLC), the rates of brain metastases were observed to be $11.8 \%$ in the placebo arm and $6.3 \%$ in the treatment arm at median follow-up of 25.2 months (16). Both of these numbers are well under what has been previously reported. It is also possible that a larger proportion of high-risk patients undergo intracranial screening MRI for metastasis, leading to earlier identification of lesions and "upstaging" of patients who would previously have been classified as having 
Table 1 Landmark studies evaluating overall survival benefit for prophylactic cranial irradiation

\begin{tabular}{|c|c|c|c|c|c|c|c|}
\hline Study & Year & $\begin{array}{l}\text { NSCLC stage } \\
\text { of patients }\end{array}$ & $\begin{array}{l}\text { Number } \\
\text { of } \\
\text { patients }\end{array}$ & $\begin{array}{l}\text { OS advantage (PCI vs. } \\
\text { observation) }\end{array}$ & $\begin{array}{l}\text { CNS-PFS advantage } \\
\text { (PCl vs. observation) }\end{array}$ & $\begin{array}{l}\text { Neuro-cognitive outcome } \\
\text { (NCO) }\end{array}$ & $\begin{array}{l}\text { Supports use of } \\
\mathrm{PCl} \text { to lengthen } \\
\text { OS? }\end{array}$ \\
\hline $\begin{array}{l}\text { RTOG } \\
0214(6)\end{array}$ & \multicolumn{2}{|c|}{2011 IIIA and IIIB } & 340 & $\begin{array}{l}\text { 10-year follow-up: } \\
17.6 \% \text { vs. } 13.3 \% \text { (NS) }\end{array}$ & $\begin{array}{l}\text { 10-year follow-up: } \\
\text { insufficient data }\end{array}$ & $\begin{array}{l}\text { 1-year follow-up: (I) MMSE: } \\
\text { NS; (II) ADLS: NS; (III) HVLT: (i) } \\
\text { immediate recall deterioration } \\
26 \% \text { vs. } 3 \%(P=0.03) ; \text { (ii) } \\
\text { delayed recall deterioration } \\
32 \% \text { vs. } 5 \% \text { ( } P=0.008)\end{array}$ & No \\
\hline $\begin{array}{l}\text { Pöttgen } \\
\text { et al. (7) }\end{array}$ & 20071 & IIIA & 112 & $\begin{array}{l}\text { 5-year follow-up: 16\% } \\
\text { vs. } 18 \%(\mathrm{NS})\end{array}$ & $\begin{array}{l}\text { 2-year follow-up: } \\
7.8 \% \text { vs. } 22.8 \% \\
\text { (95\% Cl } 15.7-53.7 \%)\end{array}$ & $\begin{array}{l}\text { Series of neuropsychiatric } \\
\text { tests completed in only } \\
11 \text { patients. NS difference }\end{array}$ & No \\
\hline Li et al. (8) & 2015 I & IIIA-N2 & 156 & 31.2 vs. 27.4 mo (NS) & $\begin{array}{l}\text { 5-year follow-up: } \\
20.3 \% \text { vs. } 49.9 \% \\
(\mathrm{P}<0.001)\end{array}$ & No dedicated NCO testing & No \\
\hline VALG (10) & 1981 & $\begin{array}{l}\text { Inoperable } \\
\text { NSCLC }\end{array}$ & 281 & $\begin{array}{l}35.4 \text { vs. } 41.4 \text { weeks } \\
\text { (NS) }\end{array}$ & $\begin{array}{l}6 \% \text { vs. } 13 \% \\
(P=0.038)\end{array}$ & No NCO & No \\
\hline SWOG (11) & 19901 & III inoperable & 254 & $\begin{array}{l}7.9 \text { vs. } 11.5 \text { mo } \\
(P=0.01 \text { favoring no } \\
P C l)\end{array}$ & $\begin{array}{l}1 \% \text { vs. } 11 \% \\
(P=0.003)\end{array}$ & No NCO & No \\
\hline $\begin{array}{l}\text { Umsawasdi } \\
\text { et al. (12) }\end{array}$ & i 1984 & $\begin{array}{l}13 \% \mathrm{I} / \mathrm{II} ; 87 \% \\
\mathrm{III}\end{array}$ & 97 & $\begin{array}{l}\text { 3-year follow-up: } \\
22 \% \text { vs. } 23.5 \% \text { (no } \\
\text { statistical analysis) }\end{array}$ & $4 \%$ vs. $23 \%(P=0.2)$ & No NCO & No \\
\hline
\end{tabular}

MMSE, Folstein Mini-Mental Status Exam; ADLS, Activities of Daily Living Scale; NS, not significant; HVLT, Hopkins Verbal Learning Test; NSCLC, non-small-cell lung cancer; CNS, central nervous system; PFS, progression-free survival; PCI, prophylactic cranial irradiation.

stage 3 disease. In other words, the population of patients diagnosed today with stage 3 NSCLC may be lower risk for metastasis overall.

Additionally, newer therapies for NSCLC, including next-generation tyrosine kinase inhibitors (TKIs) and small molecules like pemetrexed, have clinically meaningful CNS penetration. The FLAURA trial evaluating the impact of osimertinib, a third-generation epidermal growth factor receptor (EGFR) TKI, in advanced NSCLC showed development of CNS progression at $6 \%$ on treatment $v$ s. $15 \%$ with a standard EGFR-TKI (17). In a phase three study of alectinib, a third-generation anaplastic lymphoma kinase (ALK) inhibitor, 12-month cumulative incidence of CNS progression was $9.4 \%$ compared to $41.4 \%$ with crizotinib (18). There is also prospective evidence that brigatinib, a fourth-generation ALK inhibitor with EGFRinhibiting properties, has superior CNS penetration with an observed $67 \%$ intracranial progression-free survival probability at one year compared to $21 \%$ for crizotinib, a first-generation ALK inhibitor (19). The trend in NSCLC drug development has been toward better CNS penetration with lower toxicity. Some of these CNS-active drugs, like PD-1 antibody durvalumab, are also being used in earlier stage disease; as newer therapies emerge it is likely that we will continue to see improved CNS efficacy, lower toxicity, and potentially, a delay in the development of brain metastases.

The study from De Ruysscher et al., like many other PCI studies, was only able to accrue a little over half of the planned number of patients, with a large number of patients declining to add PCI to their treatment. It is possible this is due to rising concern for the neurologic impacts of PCI amongst both patients and providers. Personality changes, memory difficulty, worsening gait, motor dysfunction, and even urinary incontinence are well-described longterm side effects of exposing the entire brain to radiation. 
A recent small study of long-term SCLC survivors who received PCI demonstrated worsened cognitive outcomes at 6 and 12 months compared to patients who underwent MRI surveillance (20). Twenty-five percent of PCI patients in this study also developed gait disturbances, while no patients in the MRI surveillance group did.

It is worth noting that only one of the major PCI studies in NSCLC (Table 1) includes in-depth neuro-cognitive batteries for a large portion of the participants and it also demonstrated worse cognitive outcomes in the PCI group. Other studies [including Yamamoto et al. (21)] may rely solely on the Mini Mental State Examination (MMSE), which is a screening test that often only identifies severely affected patients and has demonstrated poor sensitivity in patients with brain tumors $(22,23)$.

In the De Ruysscher study, patients in the intervention arm had neurologic adverse events at a higher rate than those in the observation group, including some symptoms which ultimately make the primary endpoint of symptomatic brain metastasis clinically relevant. "Symptomatic," for the purposes of the study, was defined as the development of associated "signs of increased intracranial pressure, headache, nausea and vomiting, cognitive or affective disturbances, seizures, and focal neurologic symptoms." Patients receiving PCI were more likely to have headaches, nausea, vomiting, cognitive disturbances, memory impairment, and even seizures. In other words, the intervention of PCI actually tended to increase the frequency of neurologic symptoms: in this study, brain metastases were shown to be less symptomatic than radiation-related changes in both the short- and longterm. Therefore, neurologic effects of PCI should be carefully measured against the limited benefit of preventing brain metastases.

The advent of stereotactic radiosurgery (SRS) may also play a role in decreasing the use of PCI. SRS allows clinicians to avoid WBRT as salvage treatment for patients who ultimately develop brain metastases. A recent study demonstrated that survival from the treatment of up to 10 brain metastases with SRS is non-inferior to those in the treatment of just one, while preserving the MMSE score (21). At our institution, due to the lack of data supporting PCI for OS and ready access to SRS, we do not regularly recommend that patients with stage 3 NSCLC undergo PCI. We instead recommend MRI surveillance and treatment with SRS on as-needed basis. This approach is supported by the recent retrospective data published by Mamesaya et al., that showed no difference in OS in SCLC patients with limited disease and a negative baseline brain MRI who received PCI versus those followed with MRI surveillance (24).

We recognize that our comfort with surveillance over PCI may be heavily influenced by our access to MRI and SRS. A recent $7 N C C N$ article surveying the use of SRS for the four most common cancers to cause brain metastases (breast, lung, melanoma, colorectal) reported that as late as 2014 only $50 \%$ of radiation facilities reported using SRS, and that one of the most important predictive factors for SRS use is SRS on-site availability (25). While our institution was an early adopter of SRS, and SRS to greater than 3 metastases, it is worth noting that the approaches to WBRT continue to evolve; a new study on WBRT that spares the hippocampi, given concurrently with memantine, demonstrated that hippocampal avoidance may delay neurocognitive failure (26). These techniques may help reduce toxicity from treatment, improving the tolerability for patients; however, we would not predict PCI with hippocampal sparing to be superior to MRI surveillance with SRS in patients with stage 3 disease. Furthermore, we would not advocate for further study of PCI in stage 3 NSCLC without careful consideration of the contemporary overall risk that brain metastases pose in this population.

In summary, the results from De Ruysscher et al. confirm the findings of multiple previous studies using PCI in NSCLC: prevention of brain metastases with PCI in this population does not mean better OS and, in patients with access to MRI surveillance, may swap the development of minimally symptomatic brain metastases for the neurocognitive burden of irradiating the entire brain. We believe strongly that future research in PCI, WBRT, SRS, and systemic therapies intended to treat brain metastases should include neurocognitive and quality-of-life outcomes, and that these should be weighed against the increased neurologic symptom burden from radiotherapy.

\section{Acknowledgements}

None.

\section{Footnote}

Conflicts of Interest: Dr. Nagpal has consulted for Nektar Therapeutics, GW Pharmaceuticals, Abbvie, and Kiyatec. She receives research funding from Nektar Therapeutics, Berg Health, Inovio, and Tocagen. The other authors have no conflicts of interest to declare. 


\section{References}

1. De Ruysscher D, Dingemans AC, Praag J, et al. Prophylactic Cranial Irradiation Versus Observation in Radically Treated Stage III Non-Small-Cell Lung Cancer: A Randomized Phase III NVALT-11/DLCRG-02 Study. J Clin Oncol 2018;36:2366-77.

2. Stuschke M, Eberhardt W, Pöttgen C, et al. Prophylactic cranial irradiation in locally advanced non-small-cell lung cancer after multimodality treatment: long-term follow-up and investigations of late neuropsychologic effects. J Clin Oncol 1999;17:2700-9.

3. Greenspoon JN, Ellis PM, Pond G, et al. Comparative survival in patients with brain metastases from non-smallcell lung cancer treated before and after implementation of radiosurgery. Curr Oncol 2017;24:e146-51.

4. Soffietti R, Kocher M, Abacioglu UM, et al. A European Organisation for Research and Treatment of Cancer phase III trial of adjuvant whole-brain radiotherapy versus observation in patients with one to three brain metastases from solid tumors after surgical resection or radiosurgery: quality-of-life results. J Clin Oncol 2013;31:65-72.

5. Le Péchoux C, Dunant A, Senan S, et al. Standard-dose versus higher-dose prophylactic cranial irradiation (PCI) in patients with limited-stage small-cell lung cancer in complete remission after chemotherapy and thoracic radiotherapy (PCI 99-01, EORTC 22003-08004, RTOG 0212, and IFCT 99-01): a randomised clinical trial. Lancet Oncol 2009;10:467-74.

6. Gore EM, Bae K, Wong SJ, et al. Phase III comparison of prophylactic cranial irradiation versus observation in patients with locally advanced non-small-cell lung cancer: Primary analysis of Radiation Therapy Oncology Group study RTOG 0214. J Clin Oncol 2011;29:272-8.

7. Pöttgen C, Eberhardt W, Grannass A, et al. Prophylactic cranial irradiation in operable stage IIIA non small-cell lung cancer treated with neoadjuvant chemoradiotherapy: results from a German multicenter randomized trial. J Clin Oncol 2007;25:4987-92.

8. Li N, Zeng ZF, Wang SY, et al. Randomized phase III trial of prophylactic cranial irradiation versus observation in patients with fully resected stage IIIA-N2 nonsmallcell lung cancer and high risk of cerebral metastases after adjuvant chemotherapy. Ann Oncol 2015;26:504-9.

9. Russell AH, Pajak TE, Selim HM, et al. Prophylactic cranial irradiation for lung cancer patients at high risk for development of cerebral metastasis: Results of a prospective randomized trial conducted by the Radiation
Therapy Oncology Group. Int J Radiat Oncol Biol Phys 1991;21:637-43.

10. Cox JD, Stanley K, Petrovich Z, et al. Cranial irradiation in cancer of the lung of all cell types. JAMA 1981;245:469-72.

11. Mira JG, Miller TP, Crowley JJ. Chest irradiation (RT) vs. chest RT + chemotherapy \pm prophylactic brain RT in localized non small cell lung cancer: A southwest oncology group randomized study. Int J Radiat Oncol Biol Phys 1990;19:145.

12. Umsawasdi T, Valdivieso M, Chen TT, et al. Role of elective brain irradiation during combined chemoradiotherapy for limited disease non-small cell lung cancer. J Neurooncol 1984;2:253-9.

13. Lester JF, MacBeth FR, Coles B. Prophylactic cranial irradiation for preventing brain metastases in patients undergoing radical treatment for non-small-cell lung cancer: a Cochrane Review. Int J Radiat Oncol Biol Phys 2005;63:690-4.

14. Sun A, Hu C, Gore E, et al. 10-Year Updated Analysis of NRG Oncology/RTOG 0214: A Phase III Comparison of PCI vs. Observation in Patients with LA-NSCLC. Paper presented at the World Conference on Lung Cancer, Toronto Canada, Sep 2018. Abstract OA01-01.

15. Langley RE, Nankivell M, Barton R, et al. Whole brain radiotherapy for non-small cell lung cancer - Authors' reply. Lancet 2017;389:1395-6.

16. Antonia SJ, Villegas A, Daniel D. Overall survival with durvalumab versus placebo after chemoradiotherapy in stage III NSCLC: updated results from PACIFIC. Paper presented at the World Conference on Lung Cancer, Toronto Canada, Sep 2018.

17. Soria JC, Ohe Y, Vansteenkiste J, et al. Osimertinib in Untreated EGFR-Mutated Advanced Non-Small-Cell Lung Cancer. N Engl J Med 2018;378:113-25.

18. Peters S, Camidge DR, Shaw AT, et al. Alectinib versus Crizotinib in Untreated ALK-Positive Non-Small-Cell Lung Cancer. N Engl J Med 2017;377:829-38.

19. Camidge DR, Kim HR, Ahn MJ. Brigatinib vs Crizotinib in Patients With ALK Inhibitor-Naive Advanced ALK+ NSCLC: First Report of a Phase 3 Trial (ALTA-1L). Paper presented at the World Conference on Lung Cancer, Toronto Canada, Sep 2018.

20. Rusthoven CG, Kavanagh BD. Prophylactic Cranial Irradiation (PCI) versus Active MRI Surveillance for Small Cell Lung Cancer: The Case for Equipoise. J Thorac Oncol 2017;12:1746-54.

21. Yamamoto M, Serizawa T, Higuchi Y, et al. A Multi- 
institutional Prospective Observational Study of Stereotactic Radiosurgery for Patients With Multiple Brain Metastases (JLGK0901 Study Update): Irradiationrelated Complications and Long-term Maintenance of Mini-Mental State Examination Scores. Int J Radiat Oncol Biol Phys 2017;99:31-40.

22. Meyers CA, Brown PD. Role and relevance of neurocognitive assessment in clinical trials of patients with CNS tumors. J Clin Oncol 2006;24:1305-9.

23. Meyers CA, Wefel JS. The use of the mini-mental state examination to assess cognitive functioning in cancer trials: no ifs, ands, buts, or sensitivity. J Clin Oncol 2003;21:3557-8.

24. Mamesaya N, Wakuda K, Omae K, et al. Efficacy of prophylactic cranial irradiation in patients with limited-

Cite this article as: Moghavem N, Wakelee HA, Nagpal S. Case closed: another prophylactic cranial irradiation trial for stage 3 non-small cell lung cancer fails to improve overall survival. Ann Transl Med 2018;6(Suppl 2):S118. doi: 10.21037/ atm.2018.12.24 disease small-cell lung cancer who were confirmed to have no brain metastasis via magnetic resonance imaging after initial chemoradiotherapy. Oncotarget 2018;9:17664-74.

25. Kann BH, Park HS, Johnson SB, et al. Radiosurgery for Brain Metastases: Changing Practice Patterns and Disparities in the United States. J Natl Compr Canc Netw 2017;15:1494-502.

26. Gondi V, Deshmukh S, Brown PD, et al. Preservation of Neurocognitive Function (NCF) with Conformal Avoidance of the Hippocampus during Whole- Brain Radiotherapy (HA-WBRT) for Brain Metastases: Preliminary Results of Phase III Trial NRG Oncology CC001. Abstract presented at the American Society for Radiation Oncology Annual Meeting, San Antonio Texas, Oct 2018. 